\title{
AUDIT AWAL SISTEM INFORMASI PADA PT. X BERDASARKAN STANDAR CONTROL OBJECTIVES FOR INFORMATION AND RELATED TECHNOLOGY (COBIT 4.1)
}

\author{
Cindy Monica ${ }^{1}$, Leo Willyanto Santoso ${ }^{2}$, Yulia $^{3}$ \\ ${ }^{1,2,3}$ Program Studi Teknik Informatika, Fakultas Teknologi Industri, Universitas Kristen Petra \\ Jl. Siwalankerto 121-131 Surabaya 60236, Indonesia \\ Email: m26412090@john.petra.ac.id'1 , leow@petra.ac.id², yulia@petra.ac.id
}

\begin{abstract}
Abstrak: PT. X merupakan perusahaan yang bergerak dalam bidang konstruksi besi dan baja yang terletak di wilayah Surabaya. Tidak mudah bagi perusahaan yang besar dengan proses bisnisnya yang luas untuk melakukan semua proses dalam perusahaan dengan cara manual. Hal tersebut disebabkan karena pada era globalisasi sekarang ini, perusahaan harus dapat mengatasi masalah dan perubahan yang terjadi secara cepat dan sesuai sasaran. Oleh karena itu, perusahaan sangat membutuhkan aplikasi yang terintegrasi. Namun faktor yang harus diperhatikan tidak hanya berfokus pada perolehan sistem aplikasi yang dibutuhkan oleh perusahaan semata. Melainkan perusahaan juga harus berfokus untuk memelihara mutu sistem aplikasinya. Karena sistem aplikasi tersebut bermanfaat untuk mendukung dan meningkatkan manajemen perusahaan agar dapat meningkatkan kinerja perusahaan serta keefektifan dalam memberikan jasa kepada masyarakat. Maka dari itu, peneliti ingin melakukan audit awal sistem aplikasi pada PT. X dengan melakukan analisa mengenai kondisi TI pada PT. X untuk menentukan domain COBIT yang perlu untuk dilakukan audit.
\end{abstract}

Kata kunci: Audit, Sistem Informasi, COBIT 4.1

\begin{abstract}
PT. X is a company engaged in the field of iron and steel construction, located in Surabaya. Not easy for a large company with business processes that are also wide enough to carry out all processes in the company by way of the manual. This is because in the era of globalization, companies must be able to address the issues and changes that occur quickly and on target. Therefore, companies urgently need an integrated application. However, the factor that must be considered not only focuses on the acquisition of application systems needed by the company alone. But companies also need to focus on maintaining the quality of the application system. Because the application system useful to support and enhance the company's management in order to improve company performance and effectiveness in delivering services to the public. Therefore, the researcher wants to conduct the audit planning of application system for PT. $X$ with analysis on the condition of IT at PT. X to determine the COBIT domains that need to be audited.
\end{abstract}

Keywords: Audit, Information System, COBIT 4.1

\section{PENDAHULUAN}

Teknologi dan sistem informasi di dunia semakin berkembang seiring dengan berjalannya waktu. Hampir semua kebutuhan dalam hidup manusia sudah dikaitkan dengan teknologi, mulai dari kebutuhan rumah tangga, edukasi, kesehatan, dan terlebih kegiatan perkantoran maupun perusahaan. Sehingga penting bagi suatu perusahaan untuk menerapkan teknologi yang sesuai dengan proses bisnis yang ada dalam perusahaan tersebut.

PT. X merupakan perusahaan yang bergerak dalam bidang konstruksi besi dan baja yang terletak di wilayah Surabaya. Tidak mudah bagi perusahaan yang besar tersebut dengan proses bisnisnya yang juga cukup luas untuk melakukan semua proses dalam perusahaan dengan cara manual. Hal tersebut disebabkan karena pada era globalisasi sekarang ini, perusahaan harus dapat mengatasi masalah dan perubahan yang terjadi secara cepat dan sesuai sasaran. Oleh karena itu, perusahaan sangat membutuhkan aplikasi yang terintegrasi. Namun faktor yang harus diperhatikan tidak hanya berfokus pada perolehan sistem aplikasi yang dibutuhkan oleh perusahaan semata. Melainkan perusahaan juga harus berfokus untuk memelihara mutu sistem aplikasinya. Karena sistem aplikasi tersebut bermanfaat untuk mendukung dan meningkatkan manajemen perusahaan agar dapat meningkatkan kinerja perusahaan serta keefektifan dalam memberikan jasa kepada masyarakat.

Selama 2 tahun terakhir, PT. X telah menggunakan sistem aplikasi ERP (Enterprise Resource Planning) bernama INFOR yang dibeli dari PT. BSI (Business System Indonesia) Jakarta. ERP adalah sebuah aplikasi manajemen bisnis yang memudahkan pengelolaan bisnis secara terintegrasi. Sebagian besar perusahaan memperhitungkan ERP sebagai bagian penting dari suatu perusahaan. ERP mampu menyediakan informasi secara real-time mengenai proses bisnis perusahaan. Dengan menggunakan ERP, data dapat dimasukkan ke dalam sistem dari berbagai departemen. Kemudian data dapat diolah secara terpusat sehingga hanya perlu sekali saja memasukkan 
data untuk selanjutnya dimanfaatkan oleh berbagai proses bisnis lainnya. Pada intinya, ERP membantu perusahaan untuk bekerja lebih efisien dengan meminimumkan atau bahkan menghilangkan halingan arus informasi antar unit kerja atau departemen. Namun saat ini penggunaan sistem aplikasi ERP pada PT. X masih kurang maksimal. Hal ini dapat dilihat dari Key Performance Indicator (KPI) yang tidak tercapai, misalnya waktu penyelesaian pembuatan beberapa laporan yang masih terhambat.

Maka dari itu, Audit Sistem Informasi menjadi sebuah solusi untuk mengukur apakah standar perolehan dan pemeliharaan sistem aplikasi yang ada dalam perusahaan tersebut sesuai dengan standar yang telah diakui secara internasional yaitu IT governance yang terdapat pada COBIT (Control Objectives for Information and Related Technology). COBIT merupakan sebuah kerangka kerja teknologi informasi yang dipublikasikan oleh ISACA (Information System Audit and Control Association) dan digunakan karena memiliki tingkat kompleksitas yang tinggi dan cakupan yang luas. Dalam analisa ini, peneliti ingin menentukan domain COBIT yang paling sesuai dengan kondisi TI yang ada di PT. X.

\section{LANDASAN TEORI}

\section{COBIT 4.1}

Control Objective for Information and Related Technology (COBIT) adalah merupakan a set of best pratices (framework) bagi pengelolaan teknologi informasi (IT management). COBIT disusun oleh IT Governance Institute (ITGI) dan Information System Audit and Control Association (ISACA) [1]. COBIT digunakan untuk mengukur tingkat kematangan suatu proses TI dan mengukur keselarasan antara bisnis dan tujuan TI $[2,3]$. Pada penelitian ini dipilih domain PO3, AI2, dan AI5.

\section{PO3 Determine Technological Direction}

Domain PO3 menjelaskan mengenai fungsi layanan teknologi informasi dalam menentukan arah untuk mendukung kebutuhan bisnis [4, 5]. Bisnis memerlukan sebuah perencanaan infrastruktur teknologi dan arsitektur yang menetapkan dan mengatur dengan jelas dan harapan yang realistis dari teknologi yang didapat dalam menawarkan produk, layanan, dan mekanisme pengiriman. Perencanaan secara teratur meliputi aspek-aspek seperti sistem arsitektur, arah teknologi, rencana akuisisi, standar, migrasi strategi dan kontingensi. Hal ini memungkinkan terjadi tepat waktu terhadap tanggapan perubahan dalam lingkungan yang kompetitif, skala ekonomis untuk sistem informasi kepegawaian dan investasi, serta sebagai peningkatan bentuk interoperabilitas dan aplikasi.

\section{AI 2 Acquire and Maintain Application Software}

Domain AI2 menjelaskan mengenai aplikasi yang tersedia sesuai dengan kebutuhan bisnis. Proses ini meliputi desain aplikasi, pemuatan kontrol aplikasi, persyaratan keamanan, pengembangan dan konfigurasi sesuai dengan standar. Hal ini memungkinkan organisasi untuk benar mendukung operasi bisnis dengan aplikasi yang otomatis dan benar.

\section{AI 5 Procure IT Resources}

Domain AI5 meliputi sumber daya IT yaitu orang-orang, perangkat keras, perangkat lunak dan jasa IT yang perlu dibeli. Pada domain ini juga diperlukan definisi dan penegakan prosedur pengadaan, pemilihan vendor, setup pengaturan kontrak, dan kepastian bahwa organisasi memiliki semua sumber daya yang diperlukan secara tepat waktu dan hemat biaya.

\section{Metode Audit Sistem Informasi}

Dalam melaksanakan audit sistem informasi diterapkan metodologi audit sistem informasi yang sesuai dengan metodologi yang diajukan oleh IT Assurance Guide: Using COBIT. Pada dasarnya dalam metodologi audit, dilakukan metodologi pengumpulan data, yang meliputi observasi dan wawancara dilakukan dengan pihak terkait $[6,7]$. Tahapan audit tersebut adalah:

1. Penentuan audit resources

Tahap ini bertujuan mengumpulkan seluruh dokumen yang diperlukan untuk proses audit, meliputi:

- Seluruh Standard Operating Procedure (SOP) divisi IT PT. X.

- Laporan pemeliharaan sistem aplikasi bulanan divisi IT PT. X.

Selain mengumpulkan dokumen, tahap ini juga menghubungi orang-orang yang berhubungan dengan pengadaan dan perawatan aplikasi di lingkup perusahaan untuk meminta kesediaan mengisi kuesioner, melakukan interview, dan melakukan pertemuan penyamaan pendapat.

2. Evaluasi Kontrol

Tahap ini bertujuan mengetahui apakah seluruh kontrol yang telah diterapkan pada perusahaan dapat memenuhi standar yang diberikan oleh COBIT 4.1. Kontrol yang dimaksud adalah seluruh peraturan, standar prosedur, dan struktur organisasi (baik jabatan, atau divisi) yang bertanggung 
jawab terhadap proses pengadaan dan perawatan aplikasi. Tahap ini sangat penting dilakukan karena bila kontrol yang sudah ada dapat secara efektif memenuhi standar COBIT tersebut, berarti kontrol dapat digunakan sebagai standar untuk pengukuran berikutnya, yaitu Compliance Test. Tetapi bila berdasarkan evaluasi kontrol, kontrol itu sendiri tidak memadai untuk menjadi standar pengujian, maka proses pengukuran berikutnya tidak menggunakan kontrol, tetapi evaluasi substansi proses signifikan.

3. Evaluasi Kesesuaian Proses terhadap Kontrol (Compliance Test)

Tahap ini dilakukan bila kontrol dinyatakan dapat secara efektif mencapai gambaran ideal proses yang dinyatakan oleh COBIT 4.1. Tahap ini membandingkan antara proses sesungguhnya yang terjadi di lapangan dengan kontrol (peraturan, dan standar prosedur) untuk memeriksa apakah proses sesungguhnya tersebut telah dilaksanakan dengan konsisten. Juga dilakukan evaluasi apakah telah terdapat upaya monitoring yang memadai untuk melakukan evaluasi berkala proses terhadap kontrol.

4. Evaluasi Substansi Terbatas (Limited Substantive Test)

Tahap ini dilakukan setelah tahap ketiga. Walaupun pada tahap ketiga biasanya sudah dapat diketahui apakah sebuah proses dijamin (assured) dapat mencapai target proses tersebut bila sesuai (comply) terhadap kontrol, tetapi dapat terjadi bahwa kesimpulan tidak dapat diambil dengan absolut. Untuk mengatasi masalah ini maka proses-proses yang tidak dapat dievaluasi secara absolut memerlukan uji substansi dengan memanfaatkan dokumen-dokumen proses, kuesioner, dan interview terhadap pelaku proses agar dapat mengambil keputusan. Jadi tahap ini tidak dilakukan untuk seluruh aspek audit, melainkan hanya untuk proses-proses yang memerlukan pengujian lebih lanjut.

5. Evaluasi Substansi Signifikan (Significant Substantive Test)

Tahap ini dilakukan bila tahap kedua menunjukkan bahwa kontrol itu sendiri tidak dapat secara efektif mencapai gambaran ideal dari control objectives. Tahap ini dilakukan dengan metode yang sama seperti tahap keempat. Yang menjadi perbedaan adalah cakupan aspek yang diuji adalah semua aspek pengadaan dan perawatan aplikasi tanpa melihat apakah kontrol untuk aspek tersebut efektif atau tidak.

6. Pengukuran Maturity Level.

Pengukuran maturity level adalah tahapan yang bertujuan memberikan informasi level perban- dingan antara kondisi aktual dalam perpustakaan, dengan kondisi ideal yang dimiliki oleh industri. Kondisi ideal selalu dinyatakan pada level 5. Dengan membandingkan level ini diharapkan memberi informasi aspek-aspek perbaikan yang perlu dilaksanakan untuk meningkatkan level tersebut.

7. Penentuan kesimpulan dan rekomendasi.

Dengan memperhatikan hasil dari tahap kedua hingga keenam. Rekomendasi dibuat selain berdasarkan hasil evaluasi control objectives, juga memanfaatkan pengalaman dan judgement profesional dari auditor.

\section{Langkah Audit Sistem Informasi}

Langkah-langkah yang diperlukan untuk melakukan proses audit sistem informasi yaitu:

1. Pembuatan kuesioner dan wawancara ke perusahaan untuk menentukan domain audit yang sesuai.

2. Melakukan mapping antara tujuan TI dan proses TI.

3. Persiapan dan melakukan kegiatan on-site audit dan review dokumen.

4. Melakukan pengumpulan data dengan metode judgemental sampling, wawancara secara langsung, observasi, dan kuesioner.

5. Memahami strategi bisnis dan proses bisnis dari PT. X.

6. Menentukan aspek yang perlu diukur tingkat kematangan atau kedewasaanya yang bersesuaian dengan domain audit.

7. Mengukur tingkat kematangan atau kedewasaan proses sesuai dengan domain terkait.

8. Melakukan validasi internal dan eksternal ke narasumber.

9. Pengambilan kesimpulan berdasarkan hasil analisa audit sistem informasi di PT. X.

\section{PENGAMBILAN DATA}

\section{Proses Bisnis}

Proses bisnis pada PT. X adalah berawal dari adanya sebuah project yang diminta oleh pelanggan dan harus dikerjakan. Namun sebelum customer meminta untuk dibuatkan suatu project, customer dan divisi Marketing yang bertugas memasarkan jasa harus menentukan budget yang diinginkan dan telah disepakati oleh kedua belah pihak terlebih dahulu. Lalu divisi Warehouse dan Logistic harus mengecek ketersediaan stok barang yang ada di gudang sesuai dengan kebutuhan permintaan. Bila stok barang di gudang tidak ada maka divisi Warehouse dan Logistic harus melaporkannya kepada divisi Purchasing untuk 
melakukan purchase requotation untuk barang yang ingin dibeli. Lalu divisi Purchasing akan mencari supplier yang paling sesuai dengan barang kebutuhan, baik dari sisi harga maupun kualitas. Setelah memilih supplier, maka divisi Purchasing akan melakukan purchase order terhadap barang yang akan dibelinya. Kemudian setelah melakukan purchase order, divisi Purchasing akan mengkonfirmasi kepada divisi Warehouse dan Logistic untuk menyetujui kesesuaian barang yang akan dibeli dengan barang yang dibutuhkan oleh divisi Production untuk melakukan produksi. Jika divisi Warehouse dan Logistic telah menyetujui, maka barang tersebut akan dibeli dan menjadi stok yang diletakkan pada gudang. Kemudian jika stok barang di gudang sudah tersedia maka barang tersebut dapat dipakai untuk fabrikasi oleh divisi Production. Lalu divisi Warehouse dan Logistic akan membuatkan surat jalan yang akan diberikan kepada pelanggan, kemudian setelah pelanggan menerima surat jalan tersebut maka pelanggan memiliki kewajiban untuk membayar pada divisi Finance and Accounting.

\section{Struktur Organisasi}

Pada Gambar 1 dapat dilihat struktur organisasi yang terdapat pada PT. X.

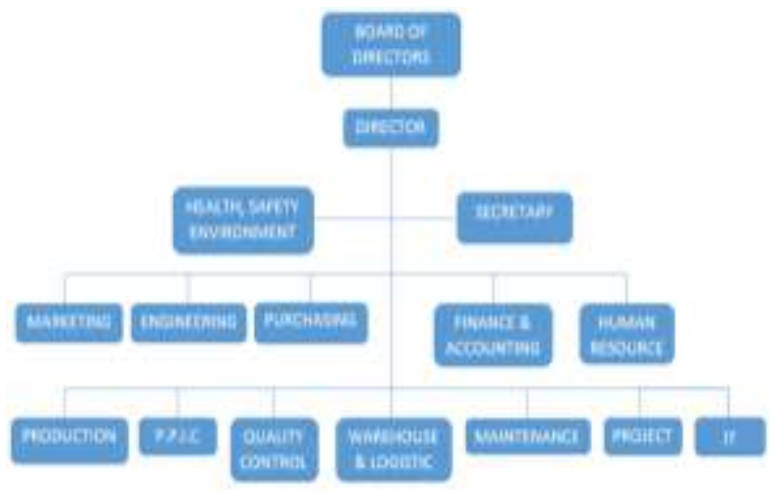

Gambar 1. Struktur Organisasi Perusahaan

\section{Visi, Misi, Target, dan Strategi}

PT. X memiliki visi yaitu:

- Menempatkan PT. X sebagai satu usaha jasa konstruksi yang utama di Indonesia.

- Menjadi penyelenggara sistem manajemen mutu dan lingkungan yang handal.

- Meraih pengakuan pelanggan atas segala pelayanan jasa PT. X.

Selain visi tersebut di atas, PT. X juga memiliki misi yaitu:

- Menghasilkan hasil usaha jasa konstruksi yang bermutu, tepat waktu, dan sesuai kondisi.
- Mengutamakan kepuasan dan hubungan baik dengan pelanggan.

PT. X juga memiliki kebijakan mutu yaitu:

- PT. X adalah perusahaan yang bergerak di bidang jasa konstruksi dengan spesialisasi bidang Civil dan Steel Construction.

- PT. X memiliki komitmen untuk secara konsisten memenuhi persyaratan pelanggan dan persyaratan perundang-undangan yang berlaku untuk dapat memenuhi kepuasan pelanggan.

- Melalui penerapan Sistem Manajemen Mutu ISO 9001: 2008, PT. X menjalankan organisasinya dengan melakukan perencanaan, pelaksanaan, pemeriksaan, tindak lanjut secara sistematis, dan melakukan perbaikan secara berkesinambungan.

Berdasarkan visi dan misi yang dimiliki oleh perusahaan, maka target perusahaan untuk ke depannya yaitu berusaha agar permintaan proyek dari pelanggan semakin meningkat. Sehingga untuk memperoleh target tersebut perusahaan memiliki beberapa strategi diantaranya adalah:

- Melayani pelanggan dengan sebaik mungkin agar pelanggan dapat merasa nyaman dan puas dengan pelayanan yang diberikan oleh PT. X.

- Mempromosikan tentang jasa yang diberikan oleh PT. X ke perusahaan-perusahaan besar yang ada di Indonesia terutama di wilayah Jawa Timur.

\section{Kondisi TI di Perusahaan}

Jumlah komputer yang dimiliki PT. X adalah 50 komputer yang berbasis Windows 7. Namun hanya 30 komputer yang tersambung dengan aplikasi INFOR, sedangkan 20 komputer lainnya tidak tersambung. Berikut spesifikasi komputer yang terdapat pada PT. X:

- Operating Systems: Microsoft Windows 7 Ultimate 32-bit.

- Processor: Intel® Core (TM) i5 CPU 3,30 GHz.

- RAM: 4 Giga Byte (GB).

- VGA: Intel® High Definition (HD) Graphics.

- HDD: 1000 Giga Byte (GB).

- Monitor: LG

- Mouse: Variant

- Keyboard: Variant

\section{ANALISA AUDIT}

\section{Audit Awal Teknologi Informasi di Perusahaan}

\section{Kuesioner COBIT}

Setelah melakukan penyebaran kuesioner COBIT kepada staff di perusahaan, maka berikut adalah hasil olahan data kuesioner dari PT. X mengenai domain pada COBIT seperti Tabel 1. 
Tabel 1. Planning and Organization (PO)

\begin{tabular}{ccc}
\hline Domain & Rata-rata & Nilai maks \\
\hline PO1 & 1,2 & 5 \\
PO2 & 1 & 5 \\
PO3 & 2,4 & 5 \\
PO4 & 0,8 & 5 \\
PO5 & 1,4 & 5 \\
PO6 & 0 & 5 \\
PO7 & 0,5 & 5 \\
PO8 & 2,2 & 5 \\
PO9 & 0,5 & 5 \\
PO10 & 0,71 & 5 \\
\hline
\end{tabular}

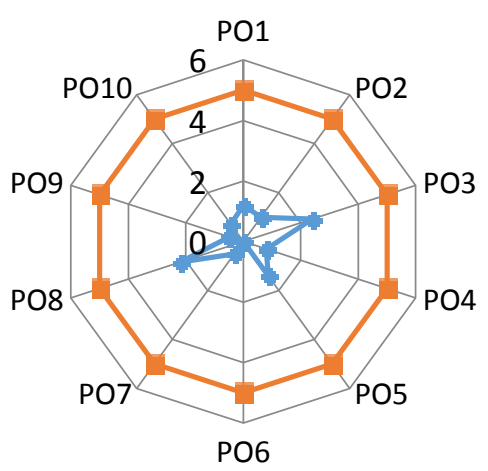

Gambar 2. Diagram Hasil Kuesioner Domain PO

Tabel 2. Acquisition and Implementation (AI)

\begin{tabular}{clc}
\hline Domain & Rata-rata & Nilai maks \\
\hline AI1 & 0,75 & 5 \\
AI2 & 2,375 & 5 \\
AI3 & 1,5 & 5 \\
AI4 & 1,167 & 5 \\
AI5 & 3 & 5 \\
AI6 & 2,2 & 5 \\
AI7 & 0,67 & 5 \\
\hline
\end{tabular}

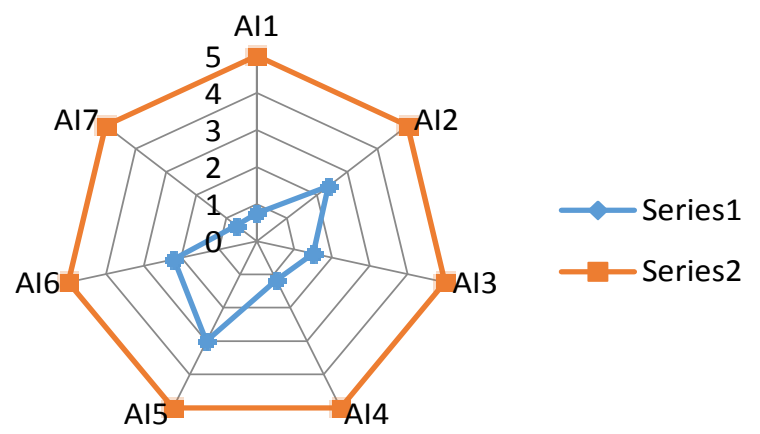

Gambar 3. Diagram Hasil Kuesioner Domain AI

Tabel 3. Monitoring and Evaluaing (ME)

\begin{tabular}{clc}
\hline Domain & Rata-rata & Nilai maks \\
\hline ME1 & 1,83 & 5 \\
ME2 & 0,43 & 5 \\
ME3 & 1 & 5 \\
ME4 & 0,4 & 5 \\
\hline
\end{tabular}

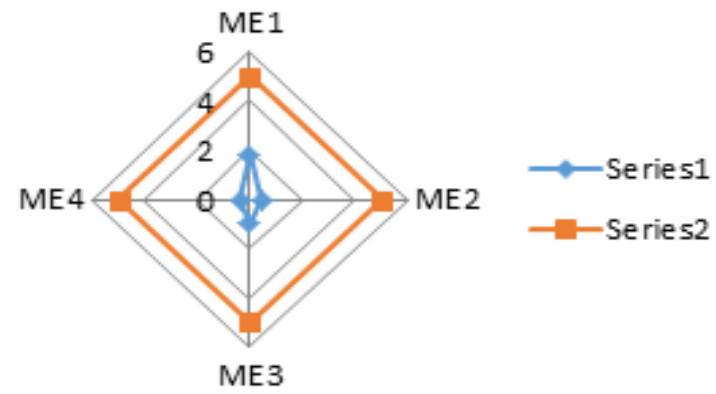

Gambar 4. Diagram Hasil Kuesioner Domain ME

Tabel 4. Deliver and Support (DS)

\begin{tabular}{clc}
\hline Domain & Rata-rata & Nilai maks \\
\hline DS1 & 0,375 & 5 \\
DS2 & 1,5 & 5 \\
DS3 & 0,83 & 5 \\
DS4 & 0,36 & 5 \\
DS5 & 1,43 & 5 \\
DS6 & 0,5 & 5 \\
DS7 & 0,8 & 5 \\
DS8 & 1,33 & 5 \\
DS9 & 0 & 5 \\
DS10 & 1,5 & 5 \\
DS11 & 1,6 & 5 \\
DS12 & 2,2 & 5 \\
DS13 & 0,57 & 5 \\
\hline
\end{tabular}

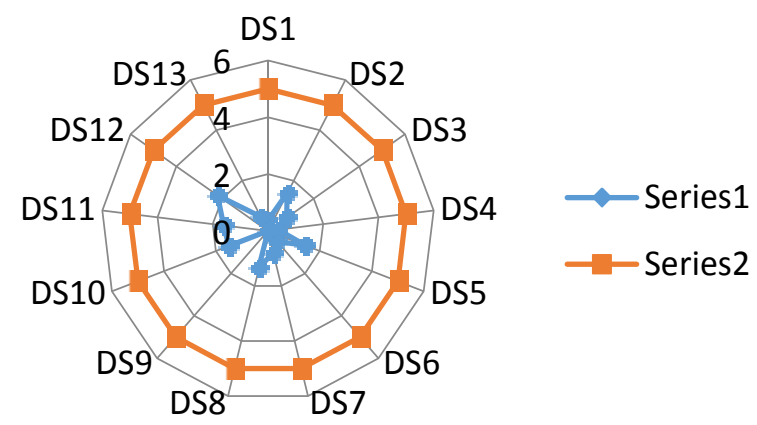

Gambar 5. Diagram Hasil Kuesioner Domain DS

Berdasarkan hasil kuesioner dari masing-masing domain di atas, maka urutan nilai rata-rata dari nilai yang tertinggi ke nilai yang terendah adalah:

\begin{tabular}{cc}
\hline Urutan hasil kuesioner & Nilai rata-rata \\
\hline AI5 & 3 \\
PO3 & 2,4 \\
AI2 & 2,375 \\
PO8 & 2,2 \\
DS12 & 2,2 \\
ME1 & 1,83 \\
DS11 & 1,6 \\
AI3 & 1,5 \\
DS2 & 1,5 \\
DS10 & 1,5 \\
DS5 & 1,43 \\
PO5 & 1,4 \\
\hline
\end{tabular}




\begin{tabular}{cl}
\hline DS8 & 1,33 \\
PO10 & 1,2 \\
AI4 & 1,167 \\
PO2 & 1 \\
ME3 & 1 \\
DS3 & 0,83 \\
PO4 & 0,8 \\
DS7 & 0,8 \\
AI1 & 0,75 \\
PO10 & 0,71 \\
AI7 & 0,67 \\
DS13 & 0,57 \\
PO7 & 0,5 \\
PO9 & 0,5 \\
DS6 & 0,5 \\
ME2 & 0,43 \\
ME4 & 0,4 \\
DS1 & 0,375 \\
DS4 & 0,36 \\
PO6 & 0 \\
DS9 & 0 \\
\hline
\end{tabular}

\section{HASIL ANALISA}

Berdasarkan jawaban yang diberikan oleh perusahaan pada pertanyaan yang peneliti ajukan dalam proses wawancara, maka hasil perhitungan dari penentuan mapping COBIT adalah sebagai berikut:

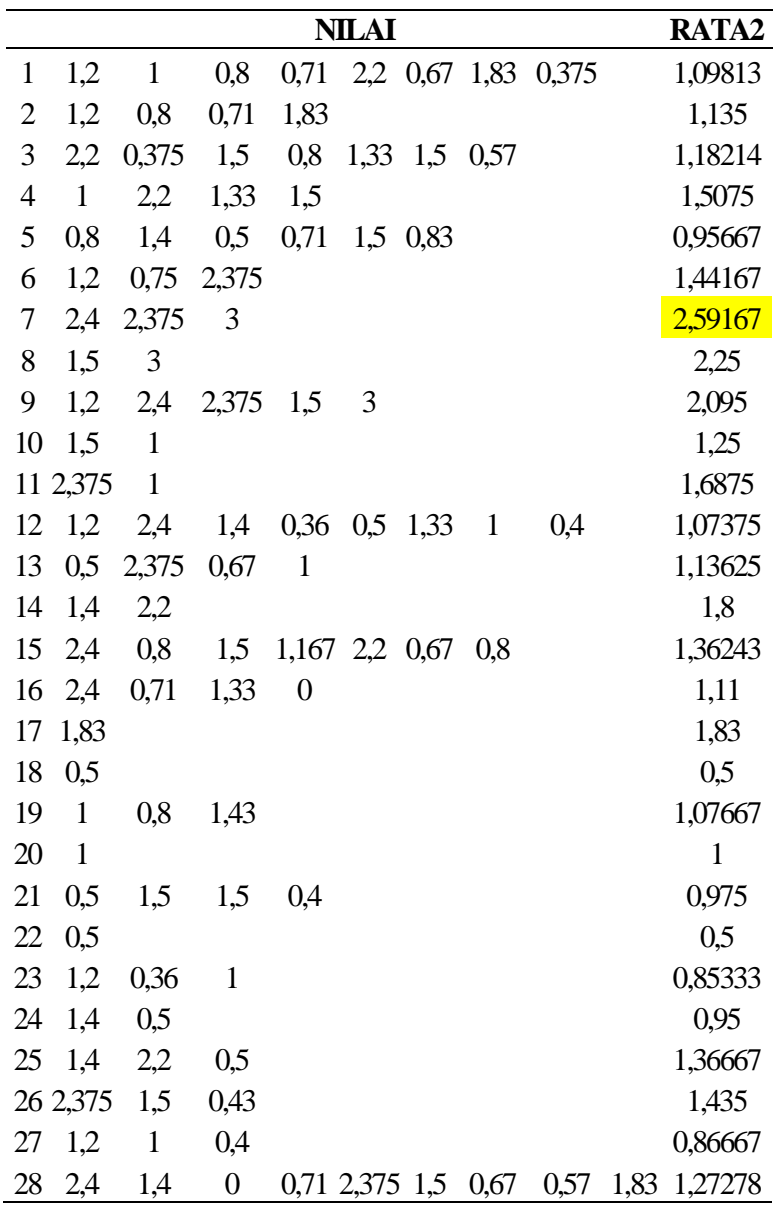

\section{KESIMPULAN DAN SARAN}

Dari penelitian yang dilakukan, ditarik beberapa kesimpulan yaitu:

1. Berdasarkan perhitungan pada analisa audit di atas, maka didapatkan hasil tertinggi adalah AI5 dengan nilai rata-rata $3, \mathrm{PO} 3$ dengan nilai rata-rata 2,4, dan AI2 dengan nilai rata-rata 2,375.

2. Berdasarkan perhitungan pada hasil analisa mapping COBIT di atas, maka didapatkan hasil tertinggi adalah nomor 7 yaitu pada bagian perolehan dan pemeliharaan sistem aplikasi yang standar dan terintegrasi yang berkaitan dengan domain $\mathrm{PO}$, $\mathrm{AI} 2$, dan AI5.

3. Sehingga diperoleh domain COBIT yang akan digunakan untuk melakukan analisa audit pada PT. X yaitu menggunakan domain PO3 yaitu Determine Technological Direction, AI2 yaitu Acquire and Maintain Application Software, dan AI5 yaitu Procure IT Resources.

Pada penelitian selanjutnya, diharapkan dalam melakukan pengumpulan data menggunakan tipe wawancara terstruktur yang telah terdiri dari daftar pertanyaan rinci untuk memudahkan penggalian informasi.

\section{DAFTAR PUSTAKA}

[1] Gondodiyoto, S. (2007). Audit Sistem Informasi Pendekatan COBIT. Jakarta: Mitra Wacana Media.

[2] Tanuwijaya, H. \& Sarno, R. (2010). Comparation of CobiT Maturity Model and Structural Equation Model for Measuring the Alignment between University Academic Regulations and Information Technology Goals. International Journal of Computer Science and Network Security, vol. 10 (no. 6), p. 80.

[3] Sarno, R. (2009). Strategi Sukses Bisnis dengan Teknologi Informasi. Surabaya: ITS Press.

[4] Information Technology Governance Institute. (2007). COBIT 4.1 Edition: Audit Guidelines, IT Governance Institute. Illinois: ITGI.

[5] Moeller, R. R. (2013). Executive's Guide to IT Governance: Improving Systems Processes with Service Management, COBIT, and ITIL. Haboken: John Wiley and Sons, Inc.

[6] Hartono, J. (2008). Metodologi Penelitian Sistem Informasi: Pedoman dan Contoh Melakukan Penelitian di Bidang Sistem Teknologi Informasi. Yogyakarta: ANDI.

[7] Sultani. (2012). Pengembangan Aplikasi Audit Sistem Informasi berdasarkan COBIT Framework di Rumah Sakit XXX. Seminar Nasional Teknologi Informasi \& Komunikasi Terapan 2012 (Semantik 2012), pp. 514-520. 